\title{
"E-books are good if there are no copies left": a survey of e-book usage at UWE Library Services
}

\author{
Jason Briddon, Jackie Chelin, Greg Ince, Jane Redman, Alastair Sleat, Elspeth \\ Williams
}

\begin{abstract}
This article outlines research carried out with students and academic staff at a large UK university library on how e-books are being used for learning, teaching and research. It was discovered that e-books are meeting many of users' needs, especially in terms of accessibility, but there are still concerns about subject coverage and the impact on students' learning. There are various reasons why ebooks are beneficial in developing an academic library collection, most particularly for reference materials and essential readings, but librarians need to work closely with academic staff to integrate use of e-books effectively into learning and teaching, taking care that licence and access implications are better understood. The drivers to the use of e-books appear to be outweighing the barriers, although the latter will require considerable effort on the part of librarians within their institutions and also in terms of communicating concerns to e-book providers.
\end{abstract}

\section{Introduction}

This article reports on the outcomes from a small scale research project at the University of the West of England (UWE) funded by the Library Information and Research Group (LIRG) / Elsevier Research Award (2007-08) ${ }^{1}$. The focus of the study was on how staff and students are using e-books for learning, teaching and research to inform library collection management and development.

The aims of the study were to discover: ${ }^{1}$ http://www.cilip.org.uk/specialinterestgroups/bysubject/research/activities/awards/researchaward.
htm

\section{Authors}

The authors are librarians working at the University of the West of England and have been engaged in this research project for around 2 years. They work in the Library's Senior Management, Academic Services and Acquisition Services teams. 
- whether e-books are meeting users' needs;

- what place there is for e-books within the context of a multidisciplinary academic library collection;

- more about the distinct drivers and barriers to the use of e-books.

As part of a consortium of libraries within the Bristol/Bath area ${ }^{2}$ we also sought to provide a set of tools that could be re-used to review the state of e-book usage in future years and at other institutions.

Having previously carried out an impact study under a LIRG initiative, UWE Library Services had already developed useful research instruments that would adapt well to this research into e-book use (Nelson et al., 2005). The methods included both quantitative and qualitative approaches:

- a web based survey aimed at students;

- semi structured interviews with academic staff;

- a small number of observed tasks undertaken by students.

Each method had its own by-products: the survey brought e-books to the attention of a wider audience; the interviews helped to consolidate relationships with academic staff and provided the opportunity for reinforcement of other messages about the library's services; the observed tasks suggested specific improvements that could be made to the library's home page and to the display of catalogue records.

The definition of e-books is a matter of great debate (Armstrong, 2008 and Vassiliou and Rowley, 2008) but for the purposes of the UWE study a clear and simple definition was agreed:

Electronic versions of titles that are, were, or could be available as hard copy books, and therefore resemble books in their structure and presentation. Examples of e-books could include textbooks, reference books (dictionaries, encyclopaedias) and law texts.

\section{Context}

UWE, Bristol is a post 1992 university, with five campuses serving around 27,000 students and over 3,000 staff. Each campus has a UWE Library.

UWE Library Services has invested heavily in e-journals over the past five years and, as a consequence, the proportion of funding spent on journals far outweighs that spent on books. As more e-book titles become available, the Library has been increasing its acquisition of e-books. However, some e-book purchasing models are subscription based, tying up even greater proportions of Library funding in ongoing commitments leaving little left for one-off purchases. Essentially the Library is trying to develop and grow the e-book collections in a way that is sustainable. One of the students actually commented in the free text section of the online survey that "E-books have to be printed to be any use, so why not go to the

${ }^{2}$ http://www.uwe.ac.uk/library/aulic/ 
original?" The biggest question this begs is how can an academic library possibly provide enough print copies? The problem is succinctly stated by Carlock and Perry of the Arizona State Library:

We do not have excess funds to purchase multiple copies while still keeping current with new publications and meeting the curriculum and research needs of our students and faculty

(Carlock, 2008, 1)

Over the last four years the Library has been working on "Reading Strategies"3 with academic staff at UWE. The Library supports academic staff in developing the information literacy of their students and managing student expectations by making available essential chapters and articles from their reading lists. This is done through a variety of means, e.g. indicating which texts students should purchase, providing scanned documents and/or linking (legally) to electronic journal articles or by distributing print study packs. The potential for e-books to support this initiative was compelling.

However, through informal discussions with students it was becoming clear that their use and expectations of electronic books might be very different from electronic journals. Were e-books more appropriate for reference only rather than essential texts as, perhaps, suggested in the study by Van Epps (2005) which was limited to electronic reference books? A study by Clark (2005) at the University of Denver, that aimed to find out how and why e-books are used, supports this idea as it suggested that students only read small portions of e-books and that print volumes are better for immersion in the text. This view was further supported by a study at Liverpool John Moores (McClelland, 2006) that found that some users want features of print books to be preserved in the electronic medium. Appleton (2004) reported on a focus group with student midwives who were encouraged to use e-books as part of a structured information skills programme and concluded that further development of e-books would be very positive, in this respect, but would need further investigation into their most effective use.

All of this suggested the need to do more research into how our students were using e-books before investing more in them and relying heavily on them to support our Reading Strategies initiative.

\section{E-book collections at UWE}

Since 2001, UWE has made individual title purchases from NetLibrary, currently accounting for around 800 titles. A lot of these were purchased on an annual renewal basis, many of which have been renewed yearly, over five years, and are therefore now in stock in perpetuity. Concurrent users are limited in the NetLibrary model.

UWE has also subscribed to a subset of the Ebrary Academic Complete service for the last three years, with unlimited concurrent user access to almost 14,000

${ }^{3}$ http://www.uwe.ac.uk/library/info/academic/toolkit/ 
titles. In addition a small number of perpetual accesses to e-books has been purchased from Ebrary, taking advantage of some financially attractive 'subject sets'. These purchases have often been single-user access.

A subscription to the Safari Books Online service has also been taken in the last year, which has provided access to approximately 500 titles with four concurrent users.

Most recently, UWE has begun purchasing individual, perpetual access titles through the Dawson ERA platform, an acquisition route proving very popular with Faculty and Subject Librarians, with the levels of access being dictated by the publisher, falling somewhere between 325 and 400 accesses per annum, on a multi concurrent user access basis.

In addition, UWE subscribes to the following services which offer a wealth of further electronic "book" content:

- Construction Information Service (CIS);

- Credo Reference;

- Early English Books Online (EEBO);

- Eighteenth Century Collections Online (ECCO);

- FORENSICnetBASE;

- Lexis Library;

- $\quad$ Literature Online (LION) ;

- Westlaw

Wherever possible, MARC records are purchased and added to the Library Catalogue.

Outside of the packages of subscribed electronic book content our individual electronic book purchases have so far been focused on NetLibrary purchases. Acquisition has been particularly successful in areas relating to Business and Management, Health, Education and the Social Sciences where the availability of relevant content has been good.

\section{Methodology}

\subsection{Survey}

An online survey methodology to find out how and if students at UWE are using e-books as part of their learning was chosen for its relative low cost, potentially fast response rate and its simplicity to complete in a short time.

The student survey had an introductory page stating the aim and also the definition of e-books, for the purposes of the survey and for those students unfamiliar with the term.

The survey consisted of 18 questions in several sections. There were six specific factual response questions requesting personal information. There were 12 behavioural questions focusing on the use and functionality of e-books, and 
preference for e-books over print. These questions required a specific response, or scaled specific response, in combination with optional open response questions about e-books.

The survey questions were chosen for their perceived ability to determine if students were successfully accessing and using e-books, for what purpose, how easy they found them to read compared with print, and also what features and functionality appealed to them or were an obstacle to their use.

The survey was available via the UWE Library Services web site for two weeks in early December 2007. These weeks fell at the end of the first semester of the academic year when it was likely that all students would have had a need to access the library catalogue and other electronic resources for their academic work. The student sample was self-selecting. The respondents had to consent to the use of the information they provided to comply with the UWE ethics guidelines and to successfully submit the survey. All respondents were asked to supply their name and e-mail address if they agreed to be contacted at a later date to participate further in the e-books study and to be included in a prize draw.

The online survey was created using commercial software, e-inform, supplied by Priority Research Ltd. The collected survey data was exported into MS Excel for manipulation and analysis.

\subsection{Interviews}

The use of semi structured interviews with academic staff was deemed the most appropriate way to find more detail and insights into the drivers and barriers of ebook usage. As indicated by Gillham:

It could be argued that the semi-structured interview is the most important way of conducting a research interview because of its flexibility balanced by structure, and the quality of the data so obtained.

(Gillham, 2005, 70)

Questions focused on:

- whether and why staff were using e-books;

- how they found and accessed them;

- what role they saw for them within the academic context;

- what they considered to be their (dis)advantages;

- what their experiences of using them were;

- what they felt about recommending them to students.

The interviews were intended to last about half an hour and were recorded for transcription purposes. Faculty librarians emailed academics asking for volunteers to be interviewed, irrespective of whether or not they were currently using e-books. The respondents were necessarily self selecting, but nonetheless demonstrated a wide range of use and understanding of e-books and ideas about their application. Twelve academics were interviewed, representing a wide range of subject areas and a good mix of teaching and research foci. 
Transcripts were read by all members of the research project group in order to identify the main themes, which were then coded. Each transcript was read by two or more members of the project team in order to assign codes and to ensure consistency of application and interpretation.

\subsection{Observed task}

The use of an observed task as a method of research was chosen in order to focus on how students were actually finding and using e-books on a practical level. As indicated by Rowlands:

Libraries must move away from bean counting dubious download statistics, and get much closer to monitoring the actual information seeking behaviour of their users

(Rowlands et al., 2008, 294)

Six students were observed and videoed as they undertook two tasks. The first task was, starting at the university home page, to find an e-book on the subject of change management. The second was to find a quote by Ralph Waldo Emerson in a specified e-book and then to explore the functionality of the interface. The students were asked to describe what they were doing as they undertook the task. As the e-book they were asked to find was available in both the NetLibrary and ebrary interfaces, they were encouraged to compare and contrast the features of each. Afterwards, they were asked questions about how frequently they use online resources and whether their tutors recommend e-books.

The students were selected randomly from those who had indicated their willingness to be contacted to help with further research. The first people who responded, and who could make the dates identified for the task, were selected. Two students from the UWE MSc Information and Library Management course piloted the task. Four further observed tasks were carried out. However, these students, along with the two pilot students, included full and part-time attendance patterns, a good range of subject areas and all levels of study.

\section{Findings}

\subsection{Survey}

There were 845 respondents to the survey of which $62 \%$ indicated that they used e-books, which correlates closely with findings in the JISC funded UK National E-books Observatory project ${ }^{4}(61.8 \%)$.

Responses to the survey were received from students in all faculties, including Joint Honours (JH) students.

\footnotetext{
${ }^{4}$ http://www.jiscebooksproject.org/
} 


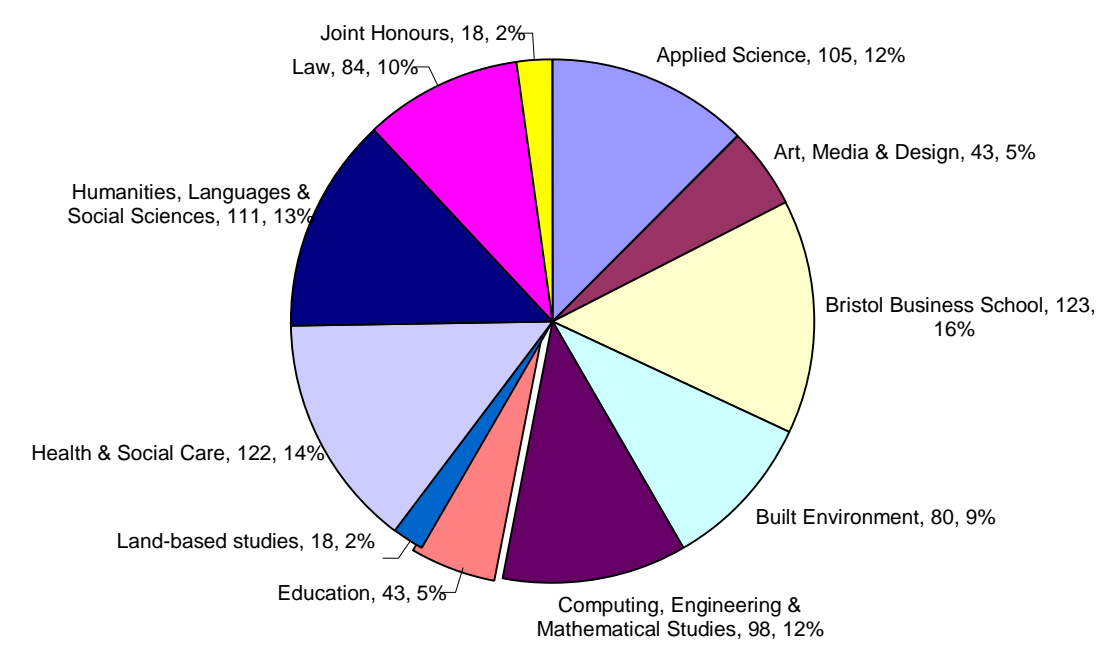

\section{Table 1: Responses by faculty}

First year students were the most likely to be non-users. Of the students who reported using e-books, Law had the highest percentage of students describing themselves as frequent users (31\%) compared with the next most frequent, Humanities, Languages and Social Sciences (HLSS) students, (21\%), and only $10 \%$ reporting frequent use in Art Media and Design (AMD). This may well reflect the electronic resources that are available to Law students, and heavily promoted through the intensive training they receive from library staff on finding information. These resources may also be more easy to use in electronic format than their print counterparts.

When asked for what type of information students used e-books, the most popular reason, cited by $76 \%$ of respondents, was 'independent reading for coursework'. This was followed, with $55 \%$, by 'reading recommended for coursework'.

Of those respondents who identified themselves as e-book users, $82 \%$ of level 3 students reported using e-books for independent reading, compared with $76 \%$ of level 2 students, $71 \%$ of level one students and $75 \%$ postgraduates.

First year undergraduates (66\%) were most likely to use e-books for recommended reading and postgraduates (PG) least (47\%). This suggests that PG students are encouraged to pursue more independent reading and research within their studies but also reflects the approach to Reading Strategies that UWE library staff have been encouraging academics to employ, i.e. advising them to provide set texts at the outset of the course, and then to ensure that students develop skills to find their own as they progress. 


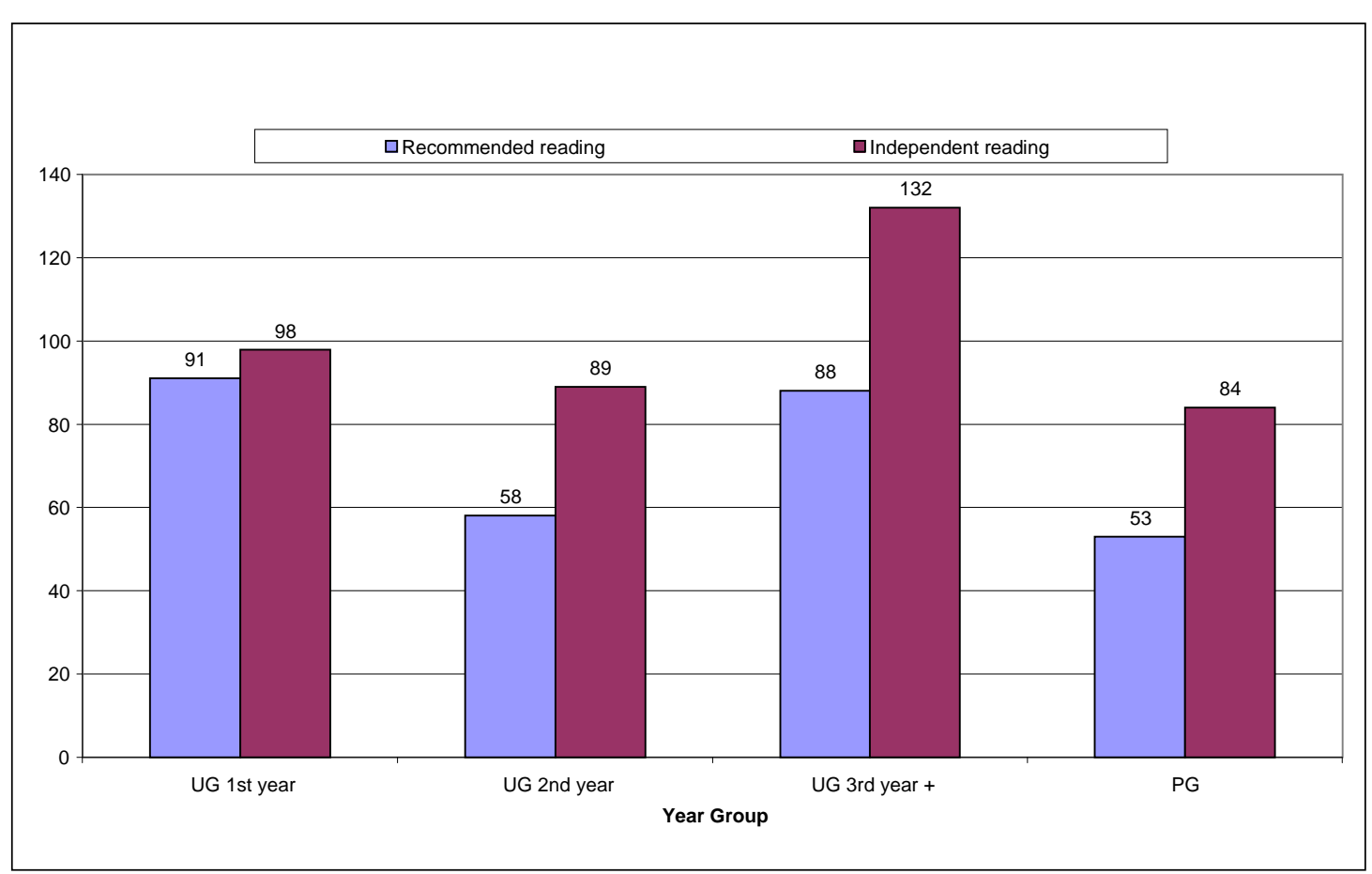

Table 2: Recommended reading by year group $\left(1^{\text {st }}, 2^{\text {nd }}, 3^{\text {rd }}\right.$ and postgraduate $)$

Reference use was reported by $27 \%$ of e-book users. Sixteen percent had used ebooks for hobbies or interests and $8 \%$ in connection with jobs or careers. In this last category usage was greatest amongst postgraduate students (13\%).

Students who reported using e-books most extensively were, not surprisingly, those within faculties whose librarians have bought/subscribed to the largest number of e-books.

Gratifyingly, the library catalogue was the most frequently cited method for finding e-books, i.e. by $57 \%$ of e-book users. Students across all years gave this as their most frequent starting point.

The question relating to how they found out about e-books was particularly interesting. As 'tutor recommendation', 'module documentation' and 'Blackboard' could be categorised as faculty sources of information on e-books, and 'library publicity', 'library catalogue', 'library web pages' and 'librarians' could be categorised as library sources, responses have been further analysed in these 2 groupings.

Forty three percent of e-book users used library sources, $41 \%$ used faculty sources and $16 \%$ used other sources, which is perhaps not so emphatically library-oriented as reported by Nicholas $(2008,326)$. Of these other sources, 'other students' comprised the most frequently cited source, closely followed by 'friends'. This indicates that faculty sources and library sources are both highly (and almost equally) important sources of information about useful e-books, and that peer recommendation is a significant influence. 


\begin{tabular}{|l|l|l|}
\hline Source & $\begin{array}{l}\text { Number of responses }(\mathbf{N} \\
\mathbf{1 1 2 1 8})\end{array}$ & $\begin{array}{l}\text { Percentage of total } \\
\text { responses }\end{array}$ \\
\hline Faculty & 500 & $41 \%$ \\
\hline Library & 522 & $42.9 \%$ \\
\hline Other (Peer) & 196 & $16.1 \%$ \\
\hline
\end{tabular}

\section{Table 3: Recommendations by faculty, library and other}

The questions about ease of use prompted more polarised responses. Ninety one percent of e-book users rated e-books as 'easy' to use (73\%) or 'very easy' (18\%). Only $8 \%$ rated them as 'poor' and $1 \%$ as 'very poor'.

The major appeal of e-books is clearly their accessibility with $88 \%$ of the 2214 responses to this question citing '24/7 availability', $77 \%$ indicating 'instant online access' was appealing and $68 \%$ that 'no visit to the library was necessary'. Issues of basic functionality were the next most appealing, with 'ability to search' being the most important, followed by 'ability to download', then 'print', 'change font size' and 'personalise'.

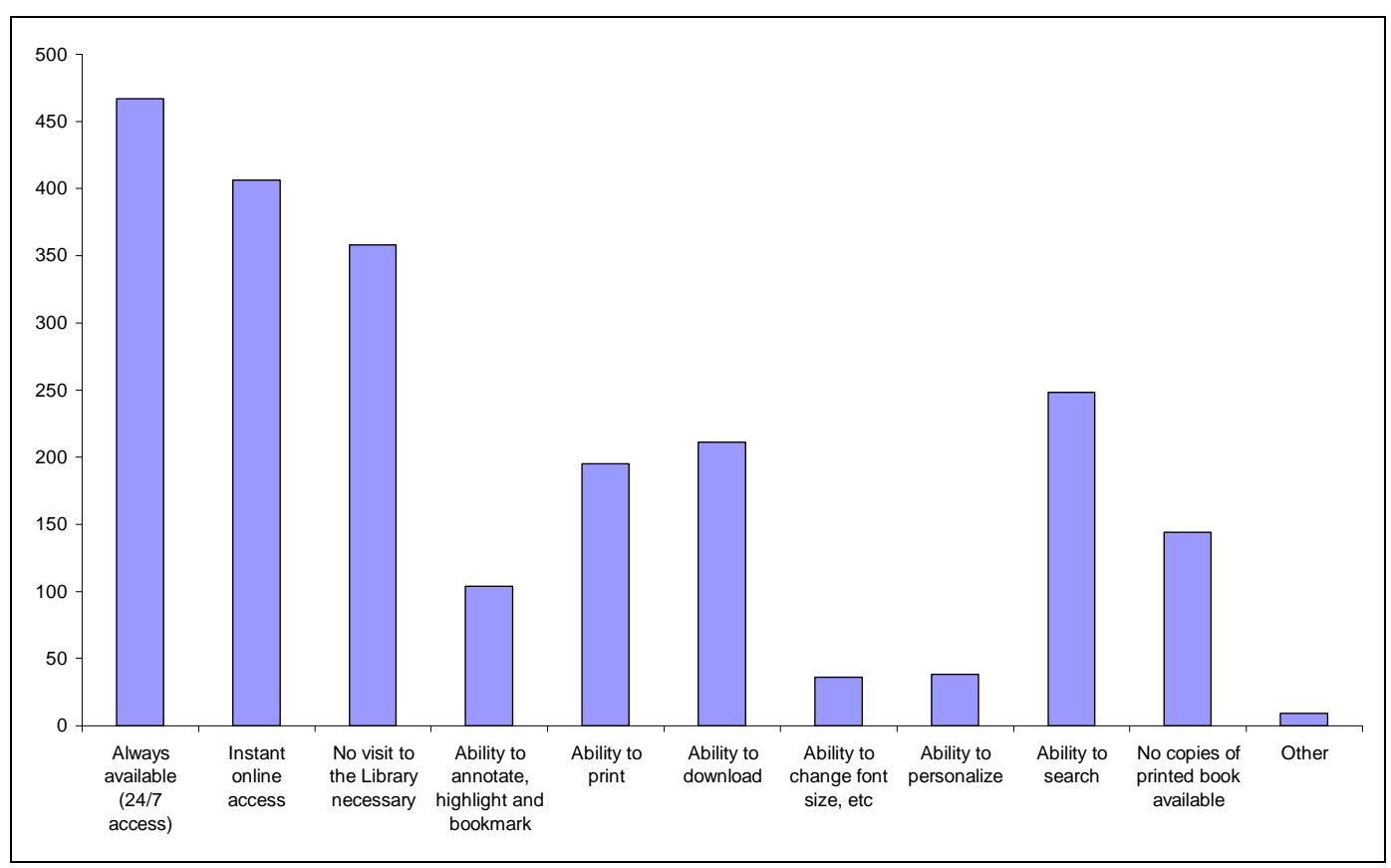

\section{Table 4: Appeal of e-book features/functionality}

Only $6 \%$ of e-book users gave the reason 'no printed copies of books available' as an attractive feature. This is interesting in the light of responses to the question asking whether they prefer e-books to print. Overall, $32 \%$ of e-book users preferred print, $17 \%$ preferred e-books, while $51 \%$ had no preference.

More sophisticated functionality does not appear to be particularly important to students, but $20 \%$ appreciated the ability to annotate, highlight and bookmark; $7 \%$ liked the personalisation features and $7 \%$ liked the options to change font size etc. There do not appear to be any significant variations between faculties on this. 
When asked why they do not use e-books, students cited the most common reason as 'don't know about them', which may be construed as a criticism of the library's promotional efforts. This raises wider issues about the best way to promote e-books, the role of serendipity, the use of the catalogue as a promotional tool and how to alert those students about e-books who do not use the catalogue.

Further insights from the free text comments on the survey might help to shed some more light on the findings. When asked why they preferred print books, the comments fell into 8 main categories. By far the largest number of comments related to the fact that print books were easier to read - the issue of eye strain was a major deterrent to use of e-books. This was followed, in popularity, by:

- the physical aspects (some students not only liking the look and feel, but also the smell of print books and "I also remember where information is on a page");

- the fact that no technology is required ("they don't crash or shut down unexpectantly" [sic]);

- the ability to easily annotate print texts;

- the fact that it is easier to concentrate when reading a print book (including "it sinks in better when I read from a book");

- a lack of awareness of e-books;

- the reliability of print books;

- their availability in print format (or lack of availability in electronic form).

These reasons are similar to those mentioned in Anhurahda and Usha $(2006,51)$ at the Indian Institute of Science, and also by McKnight et al. (2008) within the UK public library context.

When asked for any further free text comments about e-books on the survey form, the 298 responses fell into 7 main areas. Issues relating to accessibility were the most frequently mentioned, by nearly a third of those who commented ("a copy always accessible"; "everyone has a fair access to them"). The need for better marketing and training was mentioned by almost one fifth ("I think if I knew about e-books I would use them"; "just sort of stumbled across them”.)

\subsection{Interviews}

Of the twelve staff interviewed eight described themselves as users of e-books. Two had initially described themselves as non-users but it soon became clear, when interviewing them, that they were actually users. This does beg the question of how people perceive e-books and in what context they may have been (unknowingly) using them. It might also reflect their level of confidence, or lack of it. A range of subject areas was represented - applied sciences, economics, education, history, information sciences, law, land and property management, languages, linguistics, marketing and nursing. Some staff were more technologically oriented than others, some were more focused on research and others on learning and teaching. In relation to the latter, there were variations in their class sizes and modes of delivery. One was blind. 
Answers to the specific interview questions elicited some detailed and complex information.

\subsubsection{Whether and why academic staff use e-books}

Academics' reasons for using them, not surprisingly, included research, reference, support for distance learning students and support for their lectures. Some also commented that they used them by default if they found them on the catalogue and also when print was unavailable. There were various comments raised about the distinction between primary and secondary sources in the e-book format. ("I'm still not sure that I'd want them [the students] to use them as secondary texts....I just think that the book is probably worth understanding in its total, usually, rather than hunting through it for something and just fishing that out"). The blind academic had been using electronic texts with a screen reader for years and was most enthusiastic about the potential of e-books both for himself, and also for his students (“....not just for visually impaired users but for other print disadvantaged users, dyslexics, people with problems concentrating visually for a long time, there may be many reasons why these are going to be considerably useful...")

The reasons for not using them were similar to those identified by students in the survey, i.e. not knowing about them (and this could be lack of e-book content in their subject area), a preference for hard copy and also the fact that other demands on their time had prevented exploration of e-books.

\subsubsection{Finding and accessing e-books}

When asked how they found and accessed e-books, the following responses were forthcoming (in descending order of frequency): the Web (e.g. Google, publisher sites), library web site/catalogue, recommendations (by colleagues/librarians), ebrary, Project Gutenberg, other bibliographical tools and e-resources. This supports Milloy's view that "the routes through which users discover an e-book are varied and as yet there is no consensus" $(2007,33)$.

\subsubsection{What role for e-books?}

Academics saw various roles for e-books including essential readings (high quality content) for students, reference purposes, exploitation of primary sources and for interactive use in lectures (e.g. to demonstrate a working mechanical part). Practical aspects were also mentioned such as linking between resources and linking from the virtual learning environment direct to e-books. One academic mentioned that e-books can "allow a tutor to direct students to relevant/appropriate chapters from a range of books on a particular subject. So, advantages are very much the pick and mix facility. This is particularly good for more interdisciplinary subjects like gender and law". Some thought e-books should be complementary to print books. 


\subsection{4 (Dis)advantages}

The main advantages of e-books were seen to be their accessibility, in all respects, i.e. availability $24 / 7$ anywhere, ease of searching and also for those who can't read print. Others felt that the variety of resources was a distinct advantage and that ebooks might actually encourage reading through their intrinsic nature of being serendipitous and offering just-in-time benefits. One academic even felt that an advantage of e-books might be to reduce plagiarism. ("Providing access through Blackboard to relevant resources such as e-books may help to minimise student plagiarism as it means students are given a head start and should have more time to get on with their assignments").

Not surprisingly, however, plagiarism was included in the list of disadvantages that academics cited for e-books.

Inertia was cited frequently, i.e. the fact that if recommended texts are easily available in electronic format then students (and indeed staff themselves) might be seduced into using only these and not searching more widely for other relevant information ("There's an inertia factor. Rather than get up and come into the Library, they'll sit there and if they can't see it electronically they won't bother and unless they've got fairly clear directives from members of staff they're going to do what they can electronically"). This concurs with Sandstrom's view, mentioned in Rowlands $(2007 \mathrm{~b}, 385)$ that the principles of least effort, amongst other factors, determine information-seeking behaviour. In the same article, the point is made that users are now so dependent upon convenient desktop access that content that is not online might as well not exist.

In terms of concern for libraries, several academics thought that e-books would reduce students' library skills. ("Electronic access does make life easier for them [students] but by the same card I think there's no substitute for going in to the library, getting used to the databases and getting used to all resources.")

One academic was worried about incompetent archiving as a result of this proliferation of online text without careful bibliographic control ("over time there is a real risk with electronic publishing that there won't be a copy of certain things for comparative research").

On a practical level, many of the academics felt that it was not so easy to flick back and forth in an e-book, they rued the lack of portability, they felt that notetaking, annotation and browsing were less satisfactory and they were worried about the eye strain that might derive from screen reading.

On the more technical side, there were concerns about the time consuming aspects of learning how to use e-books, including getting to grips with the different technologies, platforms and interfaces. Most still felt that they needed to print off information from an e-book.

McKiel is quoted in Lonsdale $(2008,31)$, on the analysis of the ebrary global ebook survey, as saying that e-book collections and the research tools they provide are not well understood by a significant percentage of faculty and students. This is a concern that seems to be supported in the UWE study. A key message from Rowlands, et al., and one that challenges librarians to act quickly, is that 
Information professionals have exactly the right skills set to address the need for greater simplicity... of both raising awareness of this expensive and valuable content and making the interfaces much more standard and easier to use.

(Rowlands, 2008, 306)

There was also confusion over the different licensing models and the fact that it feels as if there is nothing to show for the cost. Of particular interest was the feeling of overload, both for academics themselves and for their students and researchers. Whilst there was considerable appreciation of the fantastic amount of information available at the click of a button, there was a feeling that people would only derive sound bites from online texts, that the information they found would have been through a keyword search, would be out of context and would lack the wider context that reading a complete text sequentially provides. ("...that's the thing that I'm working with at the moment with my students.... wanting them to understand what the advantages of keyword searching are but also trying to get them to understand that there are pitfalls and there is a problem with us not wading around things anymore.") This is particularly interesting as the "bite size chunks of information" are deemed by Nicholas et al. to be one of the reasons why e-books are likely to take off $(2008 \mathrm{a}, 312)$ but were mentioned by Godwin (in Walton and Pope, 2006, 36) as problematic in terms of information literacy training.

\subsubsection{Experiences of e-books}

One of the more positive experiences that the academics mentioned was the ability to make connections more easily between information from different sources and the fact that this can help enormously with their research. The ability to undertake textual analysis was mentioned both by the linguists and historians, something that is particularly difficult in the print context. ("I was able to sort of compare what intuitively I knew, that the readership was different but you could actually evidence it and you could evidence it in five minutes.") Academics' experience also suggests that if they had recommended an electronic book to their students they could be more confident that students would read it. Nonetheless, a couple of academics mentioned a 12 page watershed, over which students are reluctant to read any text, either in print or electronic format, which is supported by Nicholas et al. (2008b, 192).

The academics' negative experiences of e-books included stockpiling items to read, i.e. the "squirreling" behaviour identified in Rowlands et al. (2008, 295), lack of content in their subject area, variety of quality and functionality of ebooks, and copyright implications, both as a user and as an author. There was a perception on the part of some academics that publishers were either not equipped/knowledgeable enough to offer e-publishing options for the textbooks they wrote or that they would lose royalties if their books were published electronically ("The other thing is that I wonder how many authors, once they begin to understand the implications of dented sales of their titles, will support [ebooks] because as far as I understand it, the royalty on an e-book is exactly the same as on the agreement you've made with a printed page hardback/paperback book"). This echoes views expressed at the Publishers' Association annual 
conference, and reported by Reisz in the Times Higher Education (20 March 2008, 39), where it was stated that publishers' incentives to produce textbooks in electronic format are marred by "the research assessment exercise and the audit culture it generates".

\subsubsection{Recommending e-books}

The responses to this area of questioning fell into five main categories:

Content - There would need to be a system for checking for updates to editions to ensure that the recommendations weren't out of date. There was a concern that there might not be the breadth of information, yet, in electronic format.

Library - Academics were worried about sidelining the library ("[the students] think oh how can I find this article or this book on the internet for nothing, and they'll go searching around to get it for nothing rather than actually going to a library and finding the book in the library"). This was a challenge identified by Rowlands et al. (2008a, 308). Academics also recognised that they needed the services of library staff even more urgently to guide them through the e-book environment.

Equality issues - There was recognition that there would be an onus on PC ownership and, increasingly, a PC with appropriate software capabilities, multimedia features, etc. The debate about what the effect might be on less wealthy students was inconclusive - would they be more likely to rely on e-books (given that they can access them on fixed PCs across campus) than students who have the financial capability to purchase print copies for their own convenient use?

Pedagogy - When recommending an increasing number of electronic resources to students it is necessary to ensure they have the skills to evaluate them appropriately. There were real concerns about surface learning, skimming online texts and not truly getting to grips with concepts, etc. ("When getting students to use e-books tutors need to take care to promote WHY they are being recommended and HOW to use them within the context of the work being set".) This is perhaps another area where library staff could help. There were also misgivings about what might be seen as spoon feeding students, especially to those students at level 3 and PG.

Means of recommending e-books - There were discussions about whether to include e-books in the Virtual Learning Environment, on ordinary reading lists or in module handbooks. There was still felt to be a need to encourage students to use the library catalogue to find books for themselves.

\subsubsection{Staff interviews: main themes}

All in all, the main themes from the staff interviews are outlined below (in descending order of importance/frequency of mention).

- Issues relating to pedagogy, e.g. VLE, reading lists, spoon feeding: "I think we'd say, well, the digital future is probably a better one but I do think it puts new constraints and problems around our teaching practice. I think we need to catch up with that". 
- Aspects pertaining to content, e.g. availability, appropriateness, primarysecondary material: "I think we'd be mad to get anything, any sort of collected works of anything.... I think we'd be potty to get that in anything other than electronic format"; "...if they're available electronically more of them [the students] will actually read them"

- Consideration of different types of user, e.g. off campus, distance, international, print disabled: "I think e-books are great and specifically for the type of students that might be a widening participation type of student or somebody who's at home with three kids under five or got a job, can't find the time to go to the library"; "The fact that there is no due date on an e-book I can read and re-read at my convenience. Being a dyslexic, it does take me longer to get through material."

- Purpose/use, e.g. complementing print, textual analysis, reference, and research: "I like the flexibility that keyword searching gives you because it means you can expose a text to scrutiny in ways in which it was never intended."

- Issues relating to technology, e.g. hand held devices: "I think there's still resistance to some of the electronic resources that if it doesn't work the first time they don't go back."

- Social, cultural and political issues, e.g. library and archive use: "I think they're [e-books] important because they democratise the archive........and these are things that would previously be available to people who are privileged by happening to live in London and therefore have access to the British Library or people who lived in Oxford and had access to the Bodleian."

\subsection{Observed task}

Most of the students involved in the observed task indicated that they would want to print off sections of e-books, especially if using them for a seminar, although one person was just happy to screen read. Most would read a couple of chapters on screen. As indicated by Parkes:

... students do not use e-books in the same manner as they use print books - they are "hunters" seeking what they perceive to the most useful extracts from the book rather than browsing

(Parkes, 2007, 260)

A couple of students already made extensive use of online resources because of the distance they live from the University. The tensions between these competing needs/preferences exemplify the seemingly contradictory findings mentioned in Rowlands et al. (2007a, 494).

With regard to routes into the e-book, three students used the library catalogue and three used the A-Z list of e-resources to find an e-book package. Once in the e-book, students had a tendency to do what they would in print format, i.e. use the index and the contents page. Indeed, they preferred the e-book interface that looked more like a book than just a Word document. Knowledge of the print 
format of books appears to help students with the navigation and search of ebooks.

The e-book search within the library catalogue was popular, although it was noted that the option for keyword only (there is no author/title option) was limiting. Other comments on the library catalogue related to the use of the term 'Internet resource' to describe a link, which is vague, and also 'connect to resource' as it is not clear what kind of resource is meant.

Although the students generally found the relevant book for the task, they commented that the retrieval software was unforgiving of misspellings. Most of the students, when presented with a list of e-books that met their search criteria, opened up the one at the top of the list. This may indicate that they assume relevance ranking, along the lines of Google, or perhaps date order.

Searching within two different e-book platforms highlighted the difference in searching (better in NetLibrary) and functionality (more extensive in ebrary). It also demonstrated that guidance in how to get the best out of the e-book platform would be beneficial for students at the outset.

Students generally liked the options to highlight, bookmark, make notes and add to a bookshelf. They did not expect to find these features but when they did they were usually impressed. Even those who had used e-books before were not au fait with the functionality as they had not spent time exploring it. This supports the view of Safari, quoted in Lonsdale and Armstrong $(2008,31)$, that e-books are mainly used where someone has a very definite problem to solve or a research topic.

Generally, the students' use of e-books is still on a need to use rather than a preferred option basis. They are not yet making full use of the functionality. They are prepared to read on screen but only if it is essential and more convenient than any other way.

\subsection{Summary}

It was clear that the people surveyed and interviewed understood e-books in very different ways, despite our efforts to provide a definition. Questions about ebooks caused academic staff to comment more generally about electronic resources, eliciting many enthusiastic messages about them and about the library's provision. There was very much a sense that e-books are going to offer different opportunities and challenges for academic libraries and a feeling that academic staff are still finding their way and perhaps looking to library staff to help them in their endeavours to make the most of the technology within their teaching, aware that they need to understand better the possibilities they offer.

It would appear that student take-up of e-books is going to be much quicker since, as Nicholas et al. indicate, "students are far more likely to read from the screen" (2008a, 322). Even if they don't all feel it is comfortable, it may still be easier than making a long journey to a distant library.

Two of the students who did the observed tasks did not really like e-books, or would prefer to use print books. Others mentioned that if they had to rely on ebooks for recommended texts, the books really had to be available at all times and 
from anywhere, which has distinct implications for the restrictions on some of the providers' licences and functionality.

\section{Conclusions}

In drawing conclusions from the research, it is appropriate to answer our initial objectives.

\subsection{Are e-books meeting users' needs?}

Access is clearly a key factor. E-books can be available 24 hours a day to a range of people simultaneously. They are perfect for print disabled people (as long as they are well structured and designed) and they can be key word searched, as well as offering indexing and navigation, which opens up access to the contents quickly and easily.

Although people are extremely enthusiastic about the accessibility of e-books there are still some questions over availability of subject content and how soon coverage will increase to make a real difference to the learning and teaching environment in particular discipline areas ("at the moment, the range is limited and therefore you are working to somebody else's secondary list of materials").

There is reason to believe, from the interviews, that primary texts are used more frequently online than secondary texts, (the latter being, for example, textbooks that are recommended reading). The reasons for this may relate to coverage, as above, but also to some of the concerns expressed by academic staff in relation to potential (lack of) context, difficulties in sustained screen reading, surface (as opposed to deep, effective) learning, inertia and the possible reduction in information seeking or evaluation skills etc. ("I had a much kind of deeper understanding of the smaller subject area...., now I'm afraid that they [students] have a rather scanty understanding of a very broad range of sources and materials.")

\subsection{What place is there for e-books within the context of a multidisciplinary academic library collection?}

Staff interviews would suggest that there are many places for e-books within the academic library. Firstly, dictionaries and reference books are seen as much more relevant to the electronic format, being in need of constant access (in the case of the former) and constant updating (in the case of the latter). ("...but certainly anything to do with reference, anything that's updated I think we shouldn't be investing in hard copy stuff, I think given that resources are so short we should be using them online")

Secondly, the possibilities of multiple concurrent users for core readings/texts is particularly attractive (..."to encourage us to have say one e-book for each module, just somewhere on the reading list and attach that to Blackboard in the module..."). Links can be made from the virtual learning environment, used by students for the majority of their learning support, direct to particular sections of an e-book text (licence and technology permitting). 
Access to material of a relevant level and quality can be achieved through recommendations to a specific e-book, and this can also be more environmentally friendly if it saves printing onto paper. ("If you've got selected shortlist of the essential books, at least to begin with that would seem to me to be a good way to go forward.”)

Referring students to different sections in a range of e-books can provide the perfect composite set text for particular modules.

Students are encouraged to read quality sources accessed through their favoured online medium rather than relying on poor quality resources that they would otherwise use having found them through Google.

Nonetheless, the complementarities of print and electronic texts were mentioned by various people, suggesting that there is room for both for some time to come. ("I have a preference for e-books because they're easy to use but I don't think there's a reason why you can't use the two in parallel I don't think it's an either /or.")

Librarians are significant in helping at various levels:

- lobbying publishers/suppliers for appropriate licence models and functionality;

- promoting e-books, training students in their use and in evaluating online services generally;

- working with academic staff to identify the best ways of integrating e-books into teaching and learning.

The implications for collection management and development are complex. Using e-books in a similar way to a short loan collection can provide access to the titles most in demand on reading lists. Such titles might be purchased in electronic format via the traditional library book suppliers on a title by title basis. But, wider collections of traditional reference materials, and indeed, titles to broaden the range of stock within the library as a whole, might be bought through identified packages, depending greatly on the access model and pricing structure on offer. This has far reaching implications on the individual subject budgets of a multi-disciplinary library and is still evolving.

\subsection{What are the distinct drivers for use of e-books?}

Accessibility is a key feature given the frustration students feel in trying to get hold of key texts. This means that librarians need to consider carefully the kind of access models that different providers are offering and take care to ensure they are appropriate, or to negotiate/lobby for the most beneficial. OCLC's recent survey indicates that half of UK academic libraries claim their e-book usage is to support core reading lists (2008).

Increased availability of e-books across a range of subject areas will almost certainly drive up usage, not just for key texts but as students search for secondary materials to support assignments. 


\subsection{What are the distinct barriers to use of e-books?}

Lack of training and awareness of e-books is a major barrier. As indicated by Nicholas et al... "there is considerable room for.....better communication or publicity..." (2008a, 325). The need for training on and awareness about e-books was clearly articulated by students in the survey and in the observed task. Indeed, it was well demonstrated in the study by Belanger (2007) that libraries would benefit from more overtly instructing library users to access e-books via the catalogue and to provide information about which collections were covered within it. The need for training for academic staff was certainly implicit and, to a certain extent, explicit from the interviews. ("I think I should be using them [e-books]. I want to appear to my students to be doing the right thing.") As academic staff are likely to be instrumental in drawing students' attention to e-books, promoting ebooks firstly to academics is likely to reap the highest rewards.

The observed tasks suggested that students are likely to persevere in using ebooks, even if they are not finding the information they want within them, because they have been told it should be there. This raises the need for academic staff, who are recommending an e-book, to ensure that the information is readily available within it, and to understand the means of accessing it. The searching functionality of some e-book providers (and, indeed, the library catalogue) could be improved considerably, in this respect, through use of more fuzzy searching techniques.

If e-books are not available on the library catalogue many users will not find them. Therefore making them clearly available and managing expectations on their use by the provision of information about their functionality might be particularly helpful. Loading in catalogue records and keeping them up-to-date are going to be major challenges for librarians.

\section{References}

Anuradha, K.T., and Usha, H.S. (2006) Use of e-books in an academic and research environment: A case study from the Indian Institute of Science, Program 40(1), 48-62.

Appleton, L. (2004) The use of electronic books in midwifery education: the student perspective, Health Information and Libraries Journal, 21(4), 245-252.

Armstrong, C. (2008) Books in a virtual world: the evolution of the e-book and its lexicon, Journal of Librarianship and Information Science, 40(3), 193-206.

Belanger, J. (2007) Cataloguing e-books in UK higher education libraries: report of a survey, Program: Electronic Library and Information Systems, 41(3), 203216.

Carlock, D., and Perry, A.M. (2008) Exploring faculty experiences with e-books: a focus group, Library Hi Tech, 26(2), 244-254.

Clark, M.I. (2005) Electronic book usage: a survey at the University of Denver, Portal: Libraries and the Academy, 6(3), 288-299. 
Gillham, B. (2005) Research interviewing: the range of techniques. Milton Keynes: Open University Press. ,

Godwin, P. (2006) Keeping up with the Google generation: the challenge for Information Literacy teachers. In: Walton, G. and Pope, A. (eds.) Information literacy: recognising the need. London: Chandos.

Lonsdale, R., and Armstrong, C. (2008) Aggre-culture: what do e-book aggregators offer? Library and Information Update, 7(4), 28-33.

McClelland, R.J., and Hawkins, N. (2006) Perspectives on the use and development of a broad range of e-books in higher education and their use in supporting virtual learning environments, Electronic Library, 24(1), 68-82.

McKnight, C., Dearnley, J., Morris, A. (2008) Making e-books available through public libraries: some user reactions, Journal of Librarianship and Information Science, 40(1), 31-43.

Milloy, C. (2008) Promoting and embedding e-textbooks: the library challenge, Against the Grain, 20(1), 48-51.

Nelson, D., Chelin, J., Redman, J. and Shaw, P. (2005) We know we are making a difference but can we prove it? Impact measurement in a higher education library. In: Brophy, P. (ed.) Libraries without walls 6. London: Facet, 90-99.

Nicholas, D., Huntington, P., Hamid, R.J., Rowlands, I., Dobrowolski, T. (2008) Viewing and reading behaviour in a virtual environment: the full text download and what can be read into it, Aslib Proceedings: New Information Perspectives, 60(3), 185-198.

Nicholas, D., Rowlands, I., Huntington, P. (2008) UK scholarly e-book usage: a landmark survey, Aslib Proceedings: New Information Perspectives, 60(4), 311334.

OCLC (2008) Survey points to high growth in eBooks over the next year. OCLC eNews. December. URL:

http://www.oclc.org/uk/en/enews/2008/07/en_survey.htm [accessed 13.09.09]

Parkes, D. (2007) E-books from ebrary at Staffordshire University: a case study, Program: Electronic Library and Information Systems, 41(3), 253-261.

Reisz, M. (2008) Familiar text, new chapter, Times Higher Education, March 28th, 37-39.

Rowlands, I. (2007) Electronic journals and user behavior: a review of recent research, Library and Information Science Research, 29, 369-396.

Rowlands, I., Nicholas, D., Jamali, H.R., Huntington, P. (2007) What do faculty and students really think about e-books? Aslib Proceedings: New Information Perspectives, 59(6), 489-511.

Rowlands, I., Nicholas, D., Williams, P., Huntington, P., Fieldhouse, M. (2008) The Google generation: the information behaviour of the researcher of the future, Aslib Proceedings: New Information Perspectives, 60(4), 290-310. 
Van Epps, A.S. (2005) The evolution of electronic reference sources, Library Hi Tech, 23(2), 287-298.

Vassiliou, M., and Rowley, J. (2008) Progressing the definition of "e-book", Library Hi Tech, 26(3), 355-368.

\section{The Occasion}

Library Information Research Group (LIRG) and Elsevier Research Award (200708)

\section{Acknowledgement}

The authors gratefully acknowledge the $£ 1,000$ funding from LIRG and Elsevier that made this research project possible. Many thanks go also to all the UWE academics and students who took part and other library colleagues who contributed to data collection. 